\title{
Numerical Study on the Movement Laws of Overlying Strata in Shallow-Buried Stope Based on the Goaf Compaction Effect
}

\author{
Guangchao Zhang, ${ }^{1}$ Guangzhe Tao, ${ }^{1}$ Miao Chen ${ }^{D},{ }^{1}$ You Li, ${ }^{1}$ Pan $\mathrm{Li}^{2}$ and Yonghui Lai ${ }^{3}$ \\ ${ }^{1}$ College of Energy and Mining Engineering, Shandong University of Science and Technology, Qingdao 266590, China \\ ${ }^{2}$ Shandong Energy Group Co., Ltd., Jinan 250014, Shandong, China \\ ${ }^{3}$ Zhejiang Tunnel Engineering Group Co., Ltd., Hangzhou 310005, Zhejiang, China \\ Correspondence should be addressed to Miao Chen; miaochen@sdust.edu.cn
}

Received 20 July 2021; Accepted 24 August 2021; Published 3 September 2021

Academic Editor: Gan Feng

Copyright (C) 2021 Guangchao Zhang et al. This is an open access article distributed under the Creative Commons Attribution License, which permits unrestricted use, distribution, and reproduction in any medium, provided the original work is properly cited.

\begin{abstract}
This study presents an integrated approach including the theoretical analysis and numerical modelling to investigate the failure characteristics of the overlying strata in the shallow-buried stope. The mechanical characteristics of the caving zone are first revealed and then calibrated by using the double-yield model. The theoretical results show that the mechanical properties of the collapsed rock mass are closely related to its crushing expansion coefficient and uniaxial compressive strength. The vertical stress of the collapsed rock mass increases slowly with the strain and then increases exponentially after a certain critical strain. The simulation indicates that the fracture zone volume is 1.7-1.8 times that of the caving zone in the 31108 working face, and the failure volume of the overlying strata is 9-10 times that of the stope. The simulated height of the caving zone and fracture zone is $9 \mathrm{~m}$ and $20 \mathrm{~m}$, respectively. The comparison between the numerical and field measurement results demonstrates that the new evaluation method using shear-tensile strain behaviors can accurately predicate the height of the two zones. The proposed numerical method could be a viable alternative approach to two zones height calculation.
\end{abstract}

\section{Introduction}

Western China is rich in coal resources, accounting for $65 \%$ of the country's total reserves, but water resources reserves only account for $3.9 \%[1,2]$. The lack of water resources seriously limits the sustainable development of energy in Western China. Considering the serious contradiction between coal resources development and water resources protection in the western region, Qian et al. [3] presented the concept of green coal mining and water conservation mining technology in the western mining area. Accordingly, underground reservoir technology of coal mine was first proposed by Shenhua Group. In this way, water storage in goaf formed after coal mining has become an important technical way to handle the contradiction between coal mining and water resources protection in Western China. In the process of coal mining, the caving zone, fracture zone, and bending subsidence zone are formed from bottom to top with the movement of the overlying strata [4-6]. The water storage capacity of the underground reservoir is directly determined by the failure mode and height of the caving zone and fracture zone [7]. Therefore, it is urgent to understand the failure mode and height of the overlying strata during coal seam mining.

To date, many studies have been conducted to investigate the failure law of the overlying strata during underground reservoir construction. For example, Guo et al. [8] investigated the process of overburden failure transmission and further proposed a method for predicting overburden failure height. Xu et al. [9] presented the development law of a water flowing fractured zone with the breaking of the key stratum based on the key stratum theory. Huang et al. [10] proposed a method to characterize the distribution of the fractured zone by using the tensile deformation rate of the overlying strata. Yang et al. [11] performed a field observation to reveal the development law of the water flowing fractured zone of 
the soft overburden above a thick coal seam by monitoring borehole water injection leakage. Zhang et al. [12] revealed the influence of mining height and the panel layout on the height of the two zones in the soft overlying strata using discrete element numerical simulation. The above research studies provide a better understanding of the movement laws of overlying strata.

Currently, theoretical analysis, field measurement, and numerical modelling are the most used method to predict the development height of the water flowing fractured zone. There into, theoretical calculation methods are mostly based on various assumptions with low accuracy, while field measurement improves the accuracy of the measurement results, but the test process is time-consuming and difficult. Therefore, numerical simulation has become a simple and effective method for analyzing the failure characteristics of overlying strata $[13,14]$. In addition, numerical modelling can involve various influence factors in the analysis. Relevant studies have shown that the goaf compaction effect can result in characteristics changes of the overlying strata movement by providing an additional support resistance to the roof strata $[15,16]$. Nevertheless, existing studies have rarely taken this influence into account. Therefore, it is urgent to conduct numerical research on the movement laws of overlying strata considering the compaction effect of goaf.

In this study, a numerical method by using FLAC3D is presented to investigate the range of caving and fracture zones by discerning the plastic strain value of the zones in the model. In this modelling method, the compaction effect of the goaf is achieved by using the double-yield constitution model. The test site is located in the Lijiahao coal mine, Ordos City, Inner Mongolia Autonomous Region, China. The results presented in this study further improve the accuracy of numerical simulation, which is of great help to calculate the underground reservoir capacity.

\section{Project Overview}

The Lijiahao coal mine is located in Dongsheng District, Ordos City, Inner Mongolia Autonomous Region, China, with a designed production capacity of six million tons yearly. Currently, the mining seam is $3-1 \#$ coal seam. The average overburden depth and thickness of the coal seam are $201-254 \mathrm{~m}$ and $2.5-6.3 \mathrm{~m}$, respectively. The coal seam is a relatively simple structure, and the immediate roof is sandy mudstone, with an average thickness of $3.72 \mathrm{~m}$. The main roof is fine sandstone with an average thickness of $5.00 \mathrm{~m}$, and the floor is mainly sandstone. The test site is located in the 31108 working face. Figure 1 shows the coal seam histogram at this position.

\section{Goaf Compaction Theory and Its Mechanical Parameter Deduction Method}

3.1. Mechanical Properties of the Collapsed and Compacted Rock Mass. A large number of field observation data on strata movement has demonstrated that overlying strata can be divided into caving, fracture, and bending subsidence zone from bottom to top after the coal seam is excavated. The

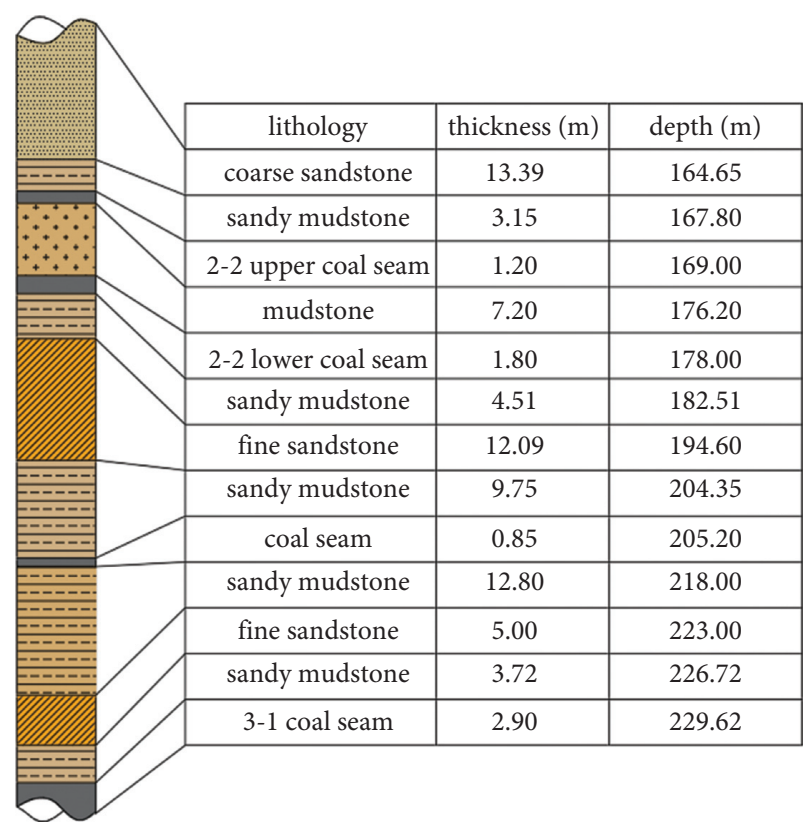

FIGURE 1: Generalized stratigraphy column of 31108 working face.

collapsed rock mass is transformed from a loose body to a supporting body under the compaction action induced by the gravity and overlying strata movement [17-19]. The fractures development and stress distribution of the overlying strata is significantly affected by the strain hardening behavior of the collapsed rock mass. Salamon [20] proposed the stress-strain relationship of rock mass in the caving zone by taking the caving block as a granular material. The expression is shown in the following equation:

$$
\sigma_{\text {cap }}=\frac{E_{0} \varepsilon}{1-\left(\varepsilon / \varepsilon_{\max }\right)},
$$

where $\sigma_{\text {cap }}, \varepsilon, \varepsilon_{\max }$, and $E_{0}$ are the vertical stress of the collapsed rock mass, the strain of collapsed rock mass under the action of vertical stress, the maximum vertical strain, and the initial elastic modulus of the collapsed rock mass, respectively. $\varepsilon_{\max }$ depends on the crushing expansion coefficient $K_{\mathrm{p}}$ of the collapsed rock mass, and the expression is as follows [21]:

$$
\varepsilon_{\max }=\frac{K_{p}-1}{K_{p}} .
$$

The relationship between the initial modulus $E_{0}$, crushing expansion coefficient $K_{\mathrm{p}}$, and compressive strength of the collapsed rock mass $\sigma_{c}$ is expressed as follows [22]:

$$
E_{0}=\frac{10.39 \sigma_{c}^{1.042}}{K_{p}^{7.7}} .
$$

Figure 2 illustrates the effect of the crushing expansion coefficient and uniaxial compressive strength on the initial modulus of a collapsed rock mass. The initial modulus of the collapsed rock mass decreases exponentially with the increase in the crushing expansion coefficient but decreases gently with the uniaxial compressive strength decreasing. 


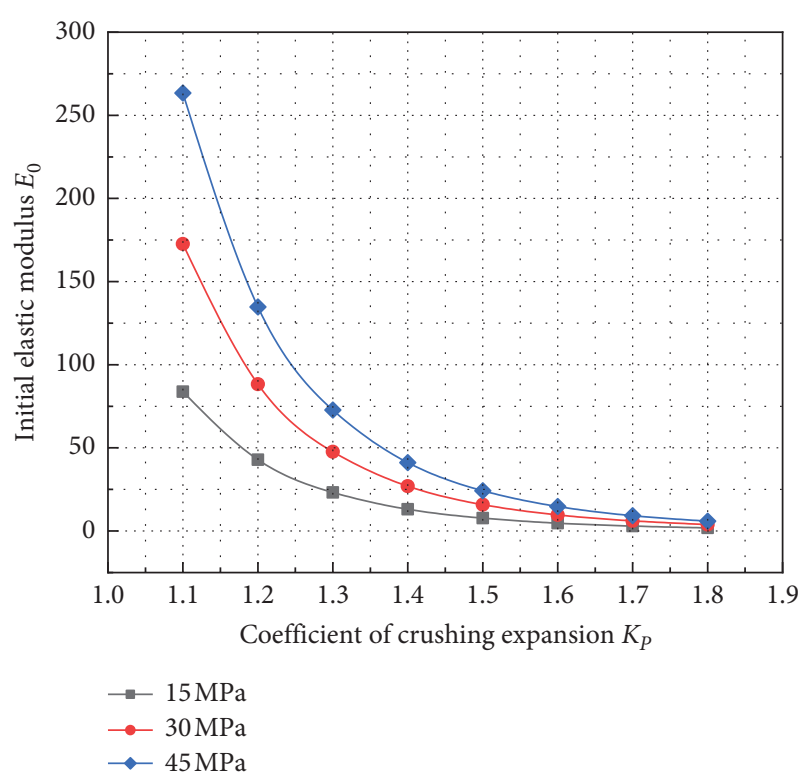

FIgURE 2: Effect of the crushing expansion coefficient and uniaxial compressive strength on the initial modulus of the collapsed rock mass.

The initial modulus of the collapsed rock mass decreases greatly when the crushing expansion coefficient is less than 1.6; conversely, it decreases gently when the crushing expansion coefficient is larger than 1.6.

From equations (1)-(3), the expression of the mechanical properties of the collapsed rock is deduced, as shown in the following equation.

$$
\sigma_{\text {cap }}=\frac{10.39 \sigma_{c}^{1.042}}{K_{p}^{7.7}} \frac{\varepsilon}{1-\left(\varepsilon K_{p} / K_{p}-1\right)} .
$$

The relationship of the stress-strain of the collapsed rock mass with different crushing expansion coefficients and the compressive strength is illustrated in Figure 3. With the strain increasing, the vertical stress of the collapsed rock mass increases slowly; and then, it increases rapidly at an exponential function when the strain reaches a certain critical value. When the crushing expansion coefficient is equal, the compressive stiffness of the collapsed rock mass increases with the increase of its uniaxial compressive strength. In other words, the strain value of the low-strength rock mass is larger than that of the high-strength rock mass with the same stress value $[23,24]$.

\subsection{Determination of Mechanical Parameters of the Caving} Zone. In this study, the double-yield constitutive model in FLAC3D is employed to depict the stress recovery behavior of collapsed rock mass, which considers the permanent volumetric strain under isotropic pressure $[25,26]$. Two kinds of parameters of cap pressure and material properties are needed in the double-yield constitutive model. And the material properties include density, bulk modulus, shear modulus, internal friction angle, and dilatancy angle. The cap pressure can be calculated by a theoretical equation,

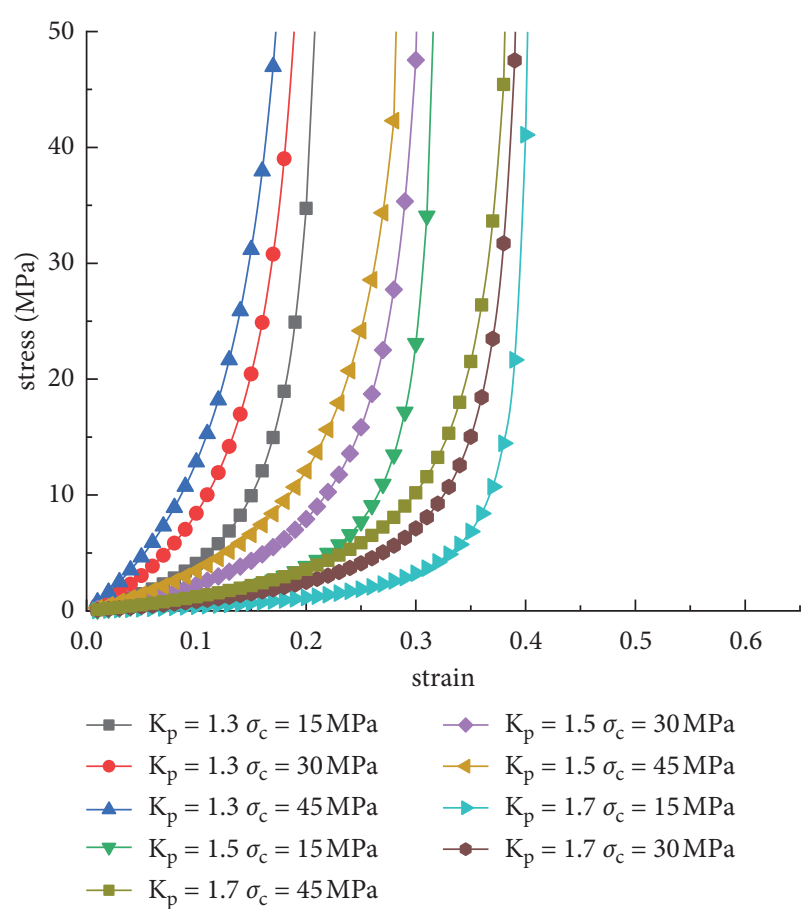

FIGURE 3: Effect of the bulking coefficient and strength of the rock mass on the mechanical property of collapsed rock masses.

while the material parameters can be determined by the "trial-and-error" method, as shown in Figure 4.

For the 31108 working face, the bulking coefficient is 1.3, and the uniaxial compression strength is $41 \mathrm{MPa}$. Based on equations (2)-(3), the maximum strain and the initial modulus of the gob materials can be estimated as 0.23 and $66 \mathrm{MPa}$, respectively. Furthermore, the cap pressures for the double-yield model are obtained and plotted in Figure 5.

A trial-and-error method was employed to determine the gob materials parameters by matching; the stress-strain curve is obtained by numerical modelling to that found by equation (1) [16]. For this purpose, a single-element submodel with dimensions $1 \mathrm{~m} \times 1 \mathrm{~m} \times 1 \mathrm{~m}$ was generated. A constant velocity was applied to the top of the model in the negative $z$-direction to generate vertical loading on the model. The velocity magnitude was set at $10-5 \mathrm{~m} / \mathrm{s}$. The displacement of the four vertical planes of the model was restricted in the normal direction, and a zero vertical displacement condition was set at the base of the model. The input parameters were calibrated by an iterative change in the bulk modulus, shear modulus, the angle of dilation, and the angle of friction of the gob materials. The final material parameters are listed in Table 1.

\section{Development Law Analysis of Water Flowing Fractured Zone in Overlying Strata}

As we all know, there are many bedding, discontinuities, and joints in coal or rock mass, which affect their failure characteristics. Although the finite difference method using FLAC3D is incapable of truly capturing their characteristics, coal or rock mass properties that are upscaled from intact 


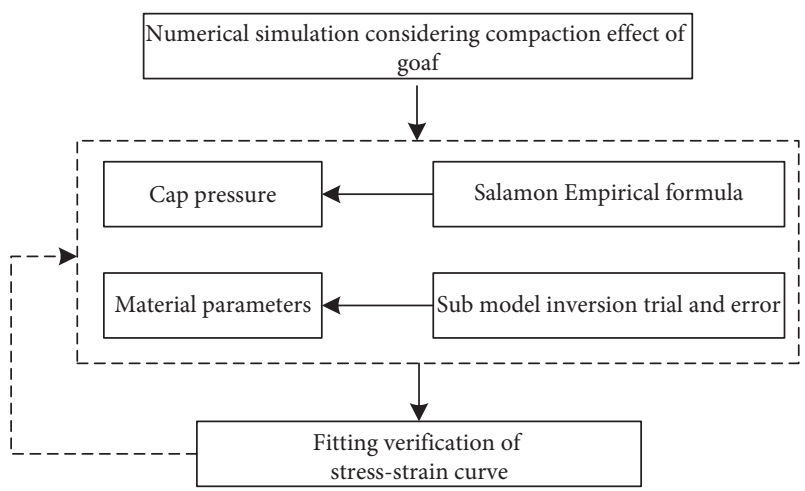

FIGURE 4: Back analysis of the parameters of the double-yield constitutive model.

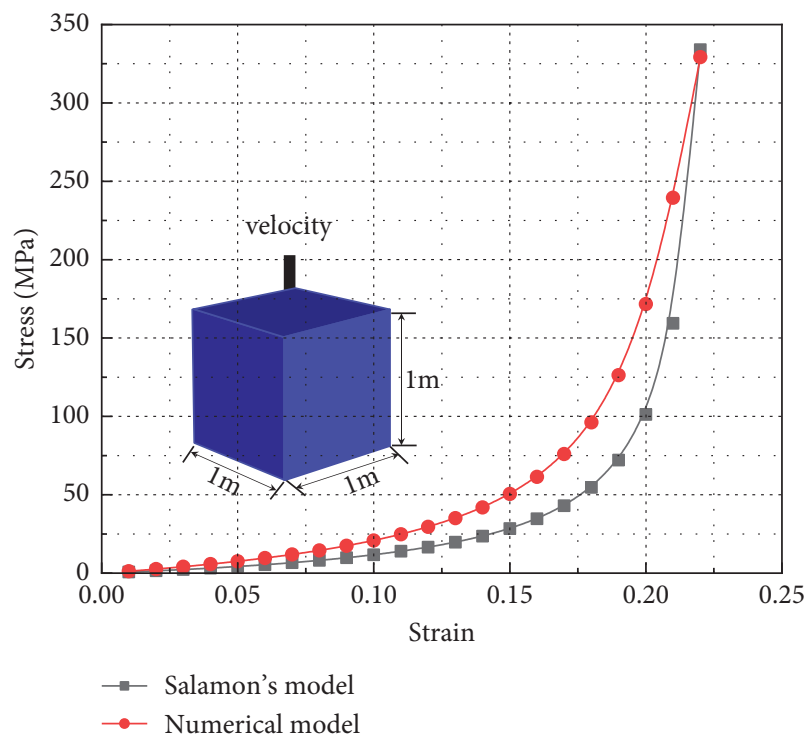

FIGURE 5: Numerical simulation inversion of mechanical properties of the double-yield model.

cores properties using the Hoek-Brown criterion can be performed in the model. In other words, the coal and rock properties in our model are effective properties that accounted for the rock discontinuities. Therefore, in this section, we use FLAC3D software to analyze the height of the caving zone and fracture zone in the 31108 working face $[2,27]$.

\subsection{Numerical Simulation Scheme}

4.1.1. Establishment of the Numerical Model. Based on the geological conditions of 31108 working face, a three-dimensional numerical calculation model was established, as shown in Figure 6. The length in the $x, \mathrm{y}$, and $z$-axis of the model is $200 \mathrm{~m}, 100 \mathrm{~m}$, and $100 \mathrm{~m}$ respectively. The thicknesses of the coal seam floor, coal seam, and overlying strata are $30 \mathrm{~m}, 3 \mathrm{~m}$, and $67 \mathrm{~m}$, respectively. The horizontal displacements of the four vertical planes of the model were restricted in the normal direction, and the vertical displacement at the base of the model was set to zero. Vertical stress of 3.25 MPa was applied at the top model boundary to simulate an overburden pressure.

The double-yield model was used for the gob modelling, and the strain-softening Mohr-Coulomb model was used for the coal and rock mass modelling. The mechanical properties for the double-yield model and strain-softening model are listed in Tables 1 and 2, respectively. Note that the mechanical properties of the coal and rock mass are calculated by the RockLab software, which is based on the generalized Hoek-Brown strength criterion [27-32].

4.1.2. Simulation Scheme and Process. Previous studies have shown that tensile failure mainly occurs in the caving zone, while shear failure mainly occurs in the fracture zone [33]. Accordingly, during the numerical simulation process, we distinguish the caving and fracture zone by the tensile and shear strain value by a self-developed FISH language. If the plastic tensile strain value of the zone is larger than 0.05 , it is judged as a caving zone, while it is judged as a rupture zone if the shear strain value is larger than 0.05 .

The modelling process is as follows. After the initial balance of the numerical model, preliminary excavation is conducted; then, the range of the caving and fracture zones is determined by the plastic tensile and shear strain values; meanwhile, the caving zone is defined as a double-yield model and calculated to equilibrium. The above modelling process is conducted circularly until the working face is mined out.

4.1.3. Analysis of Simulation Results. Figure 7 shows a threedimensional evolution diagram of the failure zone during the working face retreating, and Figure 8 shows the volume statistical analysis diagram of failed zones in two zones.

It can be inferred in Figures 7 and 8 that when the panel retreated $25 \mathrm{~m}, 50 \mathrm{~m}, 75 \mathrm{~m}$, and $100 \mathrm{~m}$, the volume of failed zones is 6.6 times, 7.59 times, 9.11 times, and 9.89 times that of the stope. Meanwhile, with the working face retreating, the volume of the failed zones increases quickly first and then tends to be stable. And the ultimate volume ratio of the failed zones and the stope maintains at 9-10. When the panel retreated $25 \mathrm{~m}, 50 \mathrm{~m}, 75 \mathrm{~m}$, and $100 \mathrm{~m}$, the volume ratio of the fracture zone to the caving zone is $1.14,1.74,1.72$, and 1.80 , respectively. It can be observed clearly that the volume ratio changes tend to be stable with the working face retreating and finally maintains 1.7-1.8 when the working face retreats to the "square" stage (the panel retreat length equates to the dip length).

Figure 9 is the height evolution law of the two zones at various retreating distances. It can be observed that the height evolution law of the caving and fracture zones kept a similar tendency, that is, it first increases rapidly and then tends to be stable with the working face retreating. When the working face retreats $25 \mathrm{~m}$, the heights of the caving and fracture zones are $6 \mathrm{~m}$ and $10 \mathrm{~m}$, respectively. And when the working face retreats $50 \mathrm{~m}$ (square stage), the height of the caving and fracture zones are $8 \mathrm{~m}$ and $16 \mathrm{~m}$, increased by $33 \%$ and $60 \%$, respectively. And furthermore, the increase 
TABLE 1: Material parameters for the double-yield model.

\begin{tabular}{lcccc}
\hline Density $\left(\mathrm{kg} / \mathrm{m}^{3}\right)$ & Bulk modulus $(\mathrm{GPa})$ & Shear modulus $(\mathrm{GPa})$ & Internal friction angle (degree) & Dilatancy angle (degree) \\
\hline 1000 & 9.58 & 5.32 & 30 & 15 \\
\hline
\end{tabular}

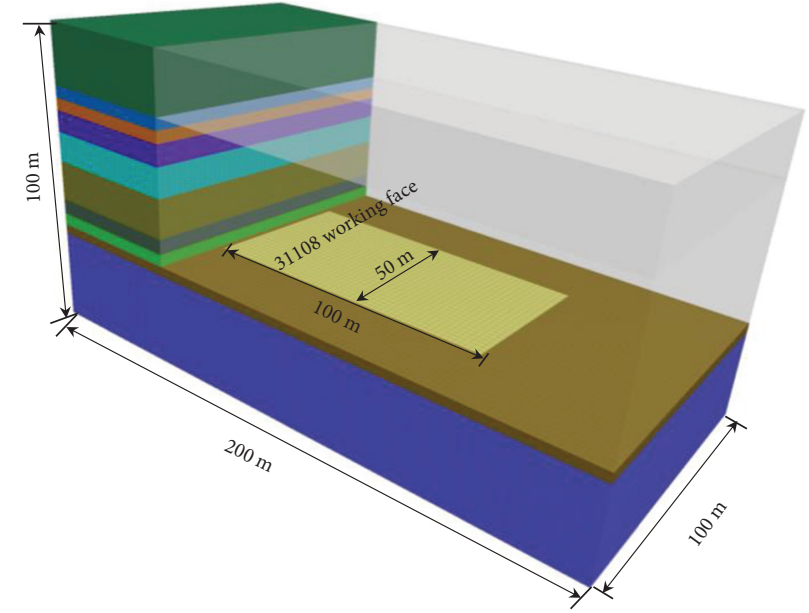

FIGURE 6: Three-dimension simulation model.

TABLE 2: Rock mass mechanical parameters of the numerical model.

\begin{tabular}{|c|c|c|c|c|c|c|c|c|c|}
\hline Rock stratum & $\begin{array}{l}\text { Density } \\
\left(\mathrm{kg} \cdot \mathrm{m}^{3}\right)\end{array}$ & $\begin{array}{c}\text { Bulk } \\
\text { modulus } \\
(\mathrm{GPa})\end{array}$ & $\begin{array}{l}\text { Shear } \\
\text { modulus } \\
(\mathrm{GPa})\end{array}$ & $\begin{array}{c}\text { Cohesion } \\
\text { (MPa) }\end{array}$ & $\begin{array}{c}\text { Internal } \\
\text { friction } \\
\text { angle } \\
\text { (degree) }\end{array}$ & $\begin{array}{c}\text { Tensile } \\
\text { strength } \\
(\mathrm{MPa})\end{array}$ & $\begin{array}{c}\text { Residual } \\
\text { cohesion } \\
(\mathrm{MPa})\end{array}$ & $\begin{array}{l}\text { Residual } \\
\text { friction angle } \\
\text { (degree) }\end{array}$ & $\begin{array}{c}\text { Softening } \\
\text { plastic } \\
\text { strain (\%) }\end{array}$ \\
\hline Floor & 2600 & 5.56 & 4.17 & 2.00 & 35 & 1.20 & 0.20 & 25 & 0.01 \\
\hline Coal seam & 1400 & 1.190 & 1.00 & 0.80 & 20 & 0.50 & 0.08 & 25 & 0.01 \\
\hline Mudstone & 2200 & 3.47 & 2.64 & 1.50 & 28 & 0.69 & 0.15 & 25 & 0.01 \\
\hline Sandy mudstone & 2200 & 2.03 & 1.56 & 1.20 & 25 & 0.80 & 0.12 & 20 & 0.01 \\
\hline Fine sandstone & 2600 & 4.56 & 3.17 & 1.22 & 26 & 0.90 & 0.12 & 25 & 0.01 \\
\hline
\end{tabular}

rate slows down when the working face retreats to $75 \mathrm{~m}$ and $100 \mathrm{~m}$, and the ultimate height of the caving and fracture zones are $9 \mathrm{~m}$ and $20 \mathrm{~m}$, increased by $12.5 \%$ and $25 \%$, respectively.

4.2. Theoretical Calculation and Field Measurement. In the longwall mining process, the height of the two zones reflects the movement characteristics of the overlying strata. Therefore, it is helpful to master the height of the two zones for the understanding of the movement law of overlying strata.

Based on the field measured data, the calculation method of the heights of two zones under different geological conditions is deduced by Bai et al. [34]. The obtained formula is as follows:

$$
\left\{\begin{array}{l}
H_{c}=\frac{100 h}{c_{1} h+c_{2}}, \\
H_{f}=\frac{100 h}{c_{3} h+c_{4}},
\end{array}\right.
$$

where $\sigma_{1}$ is the uniaxial compressive strength; $H_{\mathrm{c}}$ is the height of the caving zone; $H_{\mathrm{f}}$ is the height of the fracture zone; $c_{1}, c_{2}, c_{3}$, and $c_{4}$ are the rock strength coefficients, as given in Table 3 .

The mining height of the 31108 working face is $2.9 \mathrm{~m}$. According to the uniaxial compressive test of the roof strata, the average strength of strata in the roof is $15 \mathrm{MPa}$, which belongs to the weak rock layer. Substituting the parameters into equation (5), the heights of the caving and fracture zones are calculated to $8.5 \mathrm{~m}$ and $20.7 \mathrm{~m}$, respectively.

Studies have shown that field observation of borehole water injection leakage can obtain the height of two zones accurately [11]. In the field, a test of borehole water injection leakage was performed in a nearby working face, which has similar geological conditions to 31108 . The observation results show that the height of the caving and fracture zone is $11 \mathrm{~m}$ and $21.5 \mathrm{~m}$, respectively.

4.3. Result from Analysis. The heights of the caving zone and fracture zone obtained by numerical simulation, theoretical calculation, and field measurement are given in Table 4. It 


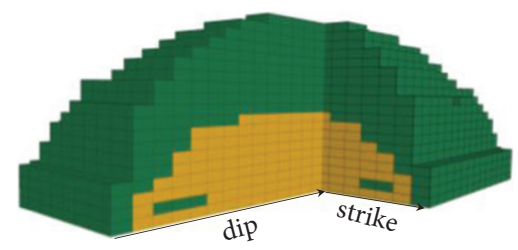

Fracture zone

Caving zone

(a)

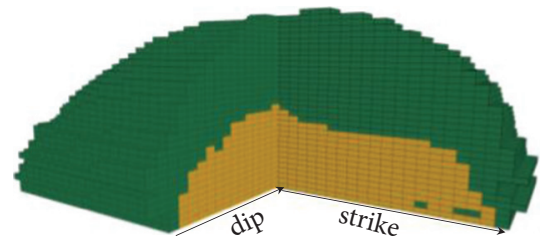

Fracture zone

Caving zone

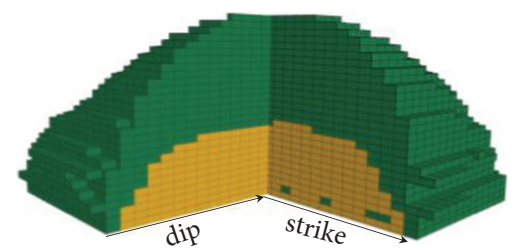

Fracture zone

Caving zone

(b)

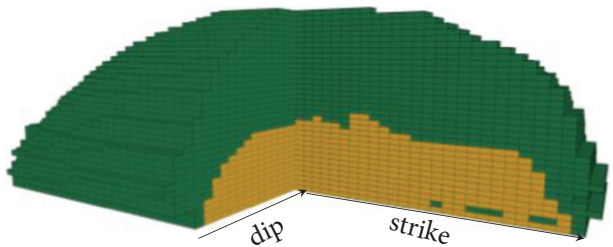

Fracture zone

Caving zone

(c)

(d)

FIgURE 7: Three-dimensional evolution diagram at various retreating distances. (a) $25 \mathrm{~m}$. (b) $50 \mathrm{~m}$. (c) $75 \mathrm{~m}$. (d) $100 \mathrm{~m}$.

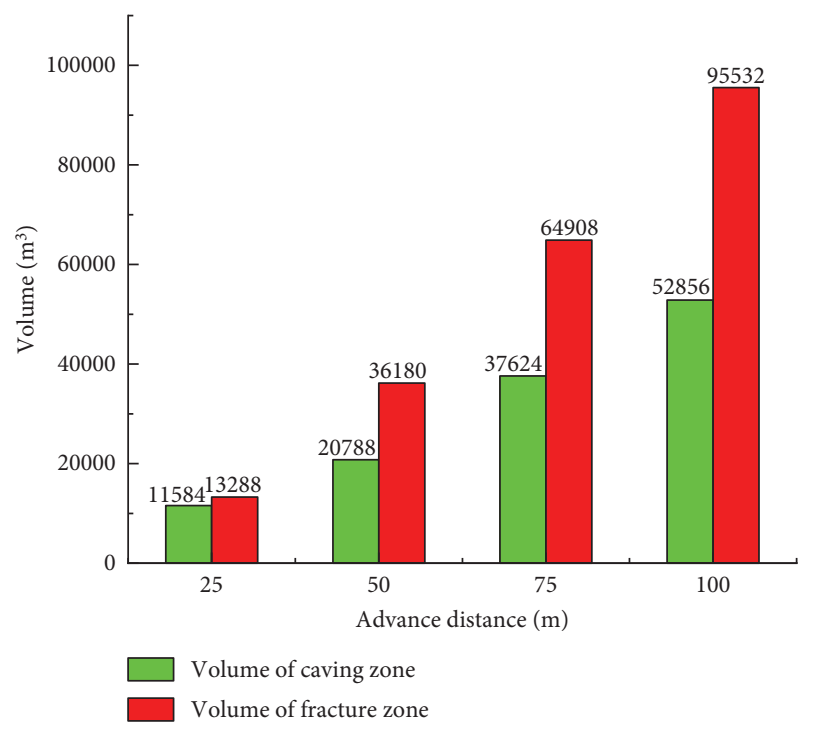

FIGURE 8: Statistical analysis chart of two zones volume.
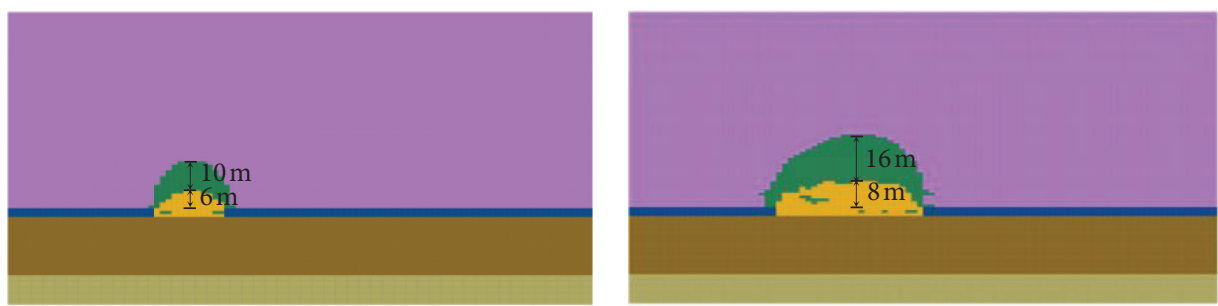

Coal

Caving zone

Coal

Caving zone

Fracture zone

F1oor1

F1oor2

Fracture zone

F1oor1

F1oor2

(a)

(b)

FIgure 9: Continued. 

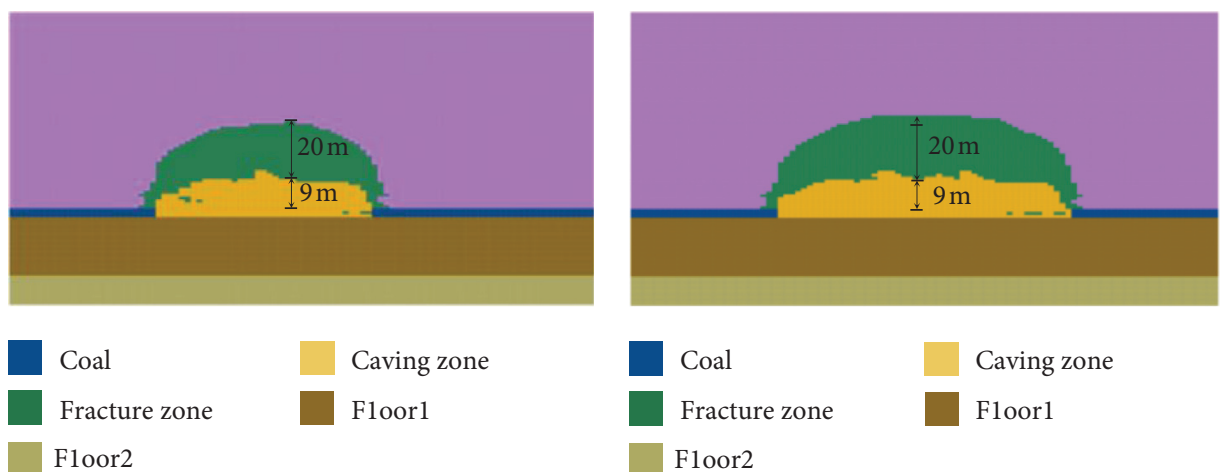

(c)

(d)

Figure 9: Height evolution law of the two zones at various retreating distances. (a) $25 \mathrm{~m}$. (b) $50 \mathrm{~m}$. (c) $75 \mathrm{~m}$. (d) $100 \mathrm{~m}$.

TABLE 3: Strength coefficient of strata in caving and fractured zones.

\begin{tabular}{lccccc}
\hline Rock type & $\sigma_{1}$ & $c_{1}$ & $c_{2}$ & $c_{3}$ & $c_{4}$ \\
\hline Hard & $>40$ & 2.1 & 16 & 1.2 & 1.6 \\
Medium & $20-40$ & 4.7 & 19 & 3.6 & 3.1 \\
Weak & $<20$ & 6.2 & 32 & 5 \\
\hline
\end{tabular}

TABLE 4: Comparison of numerical simulation and theoretical calculation results.

\begin{tabular}{lccc}
\hline & Caving zone $(\mathrm{m})$ & Fracture zone $(\mathrm{m})$ & Total $(\mathrm{m})$ \\
\hline Simulation results & 9 & 20 & 29 \\
Theoretical results & 8.5 & 20.7 & 29.2 \\
Field measurement results & 11 & 21.5 & 32.5 \\
\hline
\end{tabular}

can be observed clearly that the results obtained by simulation are less than that by the field measurement. This may be attributed to the great simplification in terms of geological conditions in the numerical model. However, within the allowable error range, the measured results and simulation results are almost the same.

It is well known that the failure mode and height of the strata overlying the stope are affected by various factors in the field, such as mining height, retreating rate, and buried depth. This study is only based on a specific geological condition of Lijiahao coal mine, and more studies are needed to prove the reliability of the numerical calculation method. However, the modelling procedure and evaluation method presented in this study are helpful to the other coal mines.

\section{Conclusions}

(1) Considering the goaf compaction effect, a new numerical simulation method by using FLAC3D is proposed to judge the fracture zone and caving zone of the overlying strata. The method can accurately predicate the height of two zones.

(2) With the strain increasing, the vertical stress of the collapsed rock mass increases slowly; and then, it increases rapidly at an exponential function when the strain reaches a certain critical value. The critical strain increases with the increase in the crushing expansion coefficient.
(3) The simulation results show that the volume of the fracture zone in the 31108 working face is 1.7-1.8 times that of the caving zone, while the rock failure is 9-10 times that of the stope. The simulated height of the caving zone and fracture zone is $9 \mathrm{~m}$ and $20 \mathrm{~m}$, respectively.

\section{Data Availability}

The data used to support the findings of this study are included within the article.

\section{Conflicts of Interest}

The authors declare that there are no conflicts of interest.

\section{Acknowledgments}

This work was supported by the National Natural Science Foundation of China (51904164 and 52004145) and the Natural Science Foundation of Shandong Province (ZR2020QE119).

\section{References}

[1] G.-C. Zhang, F.-L. He, H.-G. Jia, and Y.-H. Lai, "Analysis of gateroad stability in relation to yield pillar size: a case study," Rock Mechanics and Rock Engineering, vol. 50, no. 5, pp. 1263-1278, 2017. 
[2] G. Zhang, L. Chen, Z. Wen et al., "Squeezing failure behavior of roof-coal masses in a gob-side entry driven under unstable overlying strata," Energy Science \& Engineering, vol. 8, no. 7, pp. 2443-2456, 2020.

[3] M.-G. Qian, J.-L. Xu, and X.-X. Miao, "Green technique in coal mining," Journal of China University of Mining \& Technology, vol. 4, no. 32, pp. 343-348, 2003.

[4] Q. Wang, Y. Wang, M. He et al., "Experimental research and application of automatically formed roadway without advance tunneling," Tunnelling and Underground Space Technology, vol. 114, Article ID 103999, 2021.

[5] G. Feng, Y. Kang, X. Wang, Y. Hu, and X. Li, "Investigation on the failure characteristics and fracture classification of shale under Brazilian test conditions," Rock Mechanics and Rock Engineering, vol. 53, no. 7, pp. 3325-3340, 2020.

[6] Q. Wang, M. He, S. Li et al., "Comparative study of model tests on automatically formed roadway and gob-side entry driving in deep coal mines," International Journal of Mining Science and Technology, vol. 31, no. 4, pp. 591-601, 2021.

[7] X.-S. Kong, Z.-Z. Xu, R.-L. Shan, S. Liu, and S.-C. Xiao, "Investigation on groove depth of artificial dam of underground reservoir in coal mines," Environmental Earth Sciences, vol. 80, no. 6, 2021.

[8] W. Guo, E.-H. Bai, and G.-B. Zhao, "Current status and progress on overburden and surface damage and prevention technology of high-intensity mining," Journal of China Coal Society, vol. 45, no. 2, pp. 509-523, 2020.

[9] J.-L. Xu, W.-B. Song, and X.-Z. Wang, "New method to predict the height of fractured water-conducting zone by location of key strata," Journal of China Coal Society, vol. 37, no. 5, pp. 762-769, 2012.

[10] W.-P. Huang, Y.-F. Gao, B. Wang, and J.-R. Liu, "Evolution rule and development height of permeable fractured zone under combined-strata structure," Journal of Mining and Safety Engineering, vol. 34, no. 2, pp. 330-335, 2017.

[11] D.-M. Yang, W.-B. Guo, G.-B. Zhao, Y. Tan, and W.-Q. Yang, "Height of water-conducting zone in longwall top-coal caving mining under thick alluvium and soft overburden," Journal of China Coal Society, vol. 44, no. 11, pp. 3308-3316, 2019.

[12] G.-Y. Zhang, Q.-G. Yu, and G.-B. Zhao, "Three-dimensional simulation of soft overburden "two-zone" height due to highintensity mining in Shajihai coal mine," Journal of Mining And Strata Control Engineering, vol. 2, no. 3, Article ID 23519, 2021.

[13] L. Jing and J. A. Hudson, "Numerical methods in rock mechanics," International Journal of Rock Mechanics and Mining Sciences, vol. 39, no. 4, pp. 409-427, 2002.

[14] G. S. P. Singh and U.-K. Singh, "Assessment of goaf characteristics and compaction in longwall caving," Mining Technology, vol. 120, no. 4, pp. 222-232, 2013.

[15] Q.-S. Bai, S.-H. Tu, Y. Yuan, and F.-T. Wang, "Back analysis of mining induced responses on the basis of goaf compaction theory," Journal of China University of Mining \& Technology, vol. 369, no. 3, pp. 355-361, 2013.

[16] G.-A. Zhu, B.-W. Liu, L.-M. Dou, Y.-P. Wu, and Z.-W. Ding, "Numerical simulation for whole process of longwall mining on the basis of goaf compaction effect," Journal of China University of Mining \& Technology, vol. 48, no. 4, pp. 775-783, 2019.

[17] H. Xie, Z. Chen, and J. Wang, “Three-dimensional numerical analysis of deformation and failure during top coal caving," International Journal of Rock Mechanics and Mining Sciences, vol. 36, no. 5, pp. 651-658, 1999.

[18] K. Tajduś, "New method for determining the elastic parameters of rock mass layers in the region of underground mining influence," International Journal of Rock Mechanics and Mining Sciences, vol. 46, no. 8, pp. 1296-1305, 2009.

[19] B. Unver and N. E. Yasitli, "Modelling of strata movement with a special reference to caving mechanism in thick seam coal mining," International Journal of Coal Geology, vol. 66, no. 4, pp. 227-252, 2006.

[20] M. D. G. Salamon, "Stability, instability and design of pillar workings," International Journal of Rock Mechanics and Mining Science \& Geomechanics Abstracts, vol. 7, no. 6, pp. 613-631, 1970.

[21] M. Rezaei, M. F. Hossaini, and A. Majdi, "Determination of longwall mining-induced stress using the strain energy method," Rock Mechanics and Rock Engineering, vol. 48, no. 6, pp. 2421-2433, 2015.

[22] H. Yavuz, "An estimation method for cover pressure re-establishment distance and pressure distribution in the goaf of longwall coal mines," International Journal of Rock Mechanics and Mining Sciences, vol. 41, no. 2, pp. 193-205, 2004.

[23] Q. Yin, J.-Y. Wu, C. Zhu, M.-C. He, Q.-X. Meng, and H.-W. Jing, "Shear mechanical responses of sandstone exposed to high temperature under constant normal stiffness boundary conditions," Geomechanics and Geophysics for GeoEnergy and Geo-Resources, vol. 7, no. 2, pp. 1-17, 2021.

[24] Z. Chun, M.-C. He, X.-H. Zhang, Z.-G. Tao, Q. Yin, and L.-F. Li, "Nonlinear mechanical model of constant resistance and large deformation bolt and influence parameters analysis of constant resistance behavior," Rock and Soil Mechanics, vol. 7, p. 35, 2021.

[25] G.-C. Zhang, Y.-L. Tan, S.-J. Liang, and H.-G. Jia, "Numerical estimation of suitable gob-side filling wall width in a highly gassy longwall mining panel," International Journal of Geomechanics, vol. 8, no. 18, Article ID 4018091, 2018.

[26] G.-C. Zhang, C.-W. Zang, M. Chen et al., "Ground response of entries driven adjacent to a retreating longwall panel," International Journal of Rock Mechanics and Mining Sciences, vol. 138, Article ID 104630, 2021.

[27] E. Hoek and P.-G. Marinos, "Predicting tunnel squeezing problems in were heterogeneous rock masses," Tunnels and Tunnelling International, vol. 132, pp. 45-51, 2000.

[28] E. Hoek and E. T. Brown, "Practical estimates of rock mass strength," International Journal of Rock Mechanics and Mining Sciences, vol. 34, no. 8, pp. 1165-1186, 1997.

[29] E. Hoek, C. Carranza-Torres, and B. Corkum, "Hoek-Brown failure criterion-2002 edition," in Proceedings of the 5th North American Rock Mechanics Symposium, Toronto, Canada, July 2002.

[30] E. Hoek and Z.-T. Bieniawski, "Brittle fracture propagation in rock under compression," International Journal of Fracture, vol. 1, pp. 137-155, 1965.

[31] M. Cai, "Practical estimates of tensile strength and HoekBrown strength parameter $\mathrm{m}$ i of brittle rocks," Rock Mechanics and Rock Engineering, vol. 43, no. 2, pp. 167-184, 2010.

[32] M. Chen, S.-Q. Yang, P.-G. Ranjith, and Y.-C. Zhang, "Cracking behavior of rock containing non-persistent joints with various joints inclinations," Theoretical and Applied Fracture Mechanics, vol. 109, 2020.

[33] M. Shabanimashcool and C. C. Li, "Numerical modelling of longwall mining and stability analysis of the gates in a coal mine," International Journal of Rock Mechanics and Mining Sciences, vol. 51, pp. 24-34, 2012.

[34] M. Bai, F. Kendorski, and R. D. Van, "Chinese and north American high-extraction under-ground coal mining strata behavior and water protection experience and guidelines," in Proceedings of the 14th International Conference on Ground Control in Mining, Morgantown, WV, USA, August 1995. 